\title{
Correction to: Advanced Electrochemical Processes for the Elimination of Pharmaceutical Compounds in Contaminated Waters
}

Jelena Radjenovic and Luis Baptista-Pires

\author{
Correction to: Chapter "Advanced Electrochemical \\ Processes for the Elimination of Pharmaceutical Compounds \\ in Contaminated Waters" in: Jelena Radjenovic and \\ Luis Baptista-Pires, Hdb Env Chem, \\ https://doi.org/10.1007/698_2020_689
}

This chapter was inadvertently published with an incorrect title "Chemical Processes for the Elimination of Pharmaceutical Compounds in Contaminated Waters". The title has now been updated correctly to read as "Advanced Electrochemical Processes for the Elimination of Pharmaceutical Compounds in Contaminated Waters".

\footnotetext{
The updated online version of this chapter can be found at https://doi.org/10.1007/698_2020_689
} 